\title{
Repurposing of FDA-Approved Drugs against Mycobacterium tuberculosis Target MMA4 and CmaA2
}

\author{
Divya Umapathy ${ }^{1}$, Ranjani Soundhararajan 1 ${ }^{\text {ID }}$, Hemalatha Srinivasan 1,* (D) \\ 1 School of Life Sciences, B. S. Abdur Rahman Crescent Institute of Science and Technology, Vandalur, India \\ * Correspondence: hemalatha.sls@bsauniv.ac.in;
}

Scopus Author ID 57203969496

Received: 28.01.2021; Revised: 5.03.2021; Accepted: 10.03.2021; Published: 31.03.2021

\begin{abstract}
Tuberculosis (TB) is one of the most dreadful and deadliest diseases, killing millions annually. Its causative organism is a bacterium called Mycobacterium tuberculosis which primarily attacks the lungs. Tuberculosis can be classified as latent and active based on the presence/absence of the clinical manifestations. Also known as active TB, pulmonary TB is characterized by extreme infection, whereas in latent TB, no infection or symptom is seen. In this in silico study, we focus on the molecular docking-based virtual screening of 10 FDA-approved drugs which already used to treat bacterial infections against target methoxy mycolic acid synthase 4 (MMA4) and cyclopropane mycolic acid synthase ( $\mathrm{CmaA} 2)$. Drug-resistant TB is the most challenging factor for the design and formulation of anti-tuberculosis drugs. Mycolic acid plays a crucial role in the pathogenesis of TB and, therefore, can be an extremely valuable target. Based on a study conducted on mice, by rendering the hma genes (MMA4 and cmaA) inactive, no synthesis of mycolic acid is observed. The binding energy scores of each ligand docked against the target shows the affinity that happens against the Tuberculosis disease.
\end{abstract}

Keywords: mycolic acid; tuberculosis; molecular docking; drug resistance.

(C) 2021 by the authors. This article is an open-access article distributed under the terms and conditions of the Creative Commons Attribution (CC BY) license (https://creativecommons.org/licenses/by/4.0/).

\section{Introduction}

Mycobacterium tuberculosis causes severe bacterial infection tuberculosis remains a notable death-causing infectious disease all over the world. As per WHO report 2019 in global population, one-quarter of people are affected by TB. It causes death, majorly person tested HIV positive. In worldwide, approximately 10 million humans are affected by TB. In 2018 this count remained constant in recent years. Ailment's difficulty varies noticeably among countries, from fewer than 5 to greater than 500 newly infected with this disease per 1000000 population [1] (https://www.who.int/tb/global-report-2019). In tuberculosis classification, latent and pulmonary TB are two different types. Usually, latent TB bacteria may present inactive form, but it does not show any symptom or serious illness because of strong immune strength that has the capability to inhibit the multiplication of bacterial growth within a living system. Latent TB does not spread or infect another person. Pulmonary TB is highly infectious, causes severe infection, which may also lead to the death known as active TB; this case arises when the immune system fails to Tht against TB and inhibits the multiplication of bacterial growth [2] (https://www.cdc.gov/). The infection becomes more complex when TB patients had co-infection with HIV causes the immune system to weaken, and it is the reason for leading death cause. In India, nearly 1.8 million cases occurring per year TB co-infected with HIV, which causes immunosuppression leads to extrapulmonary TB form [3]. This co-infection and 
TB condition arise various challenging factor drug resistance classifies as Multi, extremely, and drug-resistant. Isoniazid and rifampicin are predominantly used as a first-line drug for a long-term period as a therapeutic drug to treat TB disease; during medication, infectious bacteria become resistant, known as drug resistance. The level of the resistance depends on the stage of the treatment [4].

The most challenging factor and unique characteristic of Mycobacterium tuberculosis is its lipid content present in the cell envelope, which comprises about $40 \%$ of its outer cell wall [5]. The predominant lipid component present in TB is found as mycolic acid [6]. Bacterial cell-wall synthesis remains an important target in the development of a new drug to outcome resistance [4]. Mycolic acids which are prime elements of the mycobacterial cytomembrane, high molecular weight $\left(\mathrm{C}_{60}-\mathrm{C}_{90}\right)$ of a-alkyl, b-hydroxy fatty acids, with a short, saturated arm of 20-26 carbon atoms and a long meromycolic acid arm of 50-60 carbon atoms [6]. The latter arm is comprised of cyclopropyl, a-methyl organic compound, at regular intervals, or a-methyl methyl ethers teams. The mycolic acid synthesis pathway has 5 distinct stages: synthesis of C20 to C26 straight-chain saturated fatty acids to supply the a-alkyl branch branched meromycolic acid chain to produce the carbon backbone, modification of this backbone to introduce other useful groups, the Claisen-type condensation step, which is finally followed by reduction and varied mycolyltransferase processes to cellular lipids [7]. Mycolic acid is strongly bonded with low fluidity arranged in two layers of lipids. hydroxymycolic acids highly synthesized by hma gene. No formation of mycolates, keto, and mycolates are observed in mutant inactivated hma gene [8]. The gene cmaA and MMA4 act as intermediate, and it is required in the synthesis of mycolic acid encoded enzyme transferase-initiated molecule methylates in $\alpha$-mycolic acid also evolves - $\mathrm{OH}$ group to methylated carbon that results in the formation of substrate hydroxymycolic acid to function keto into mycolic acid $[9,34,35]$.

\subsection{Target 1-MMA4.}

Methoxy mycolic acid synthase 4 (MMA4) gene present in Mycobacterium tuberculosis coded $S$-adenosylmethionine-dependent methyltransferase act as a precursor molecule in the synthesis of keto and methoxymycolic acid [12].

\subsection{Target 2-CmaA2.}

A Gene cyclopropane mycolic acid synthase (CmaA2) important for Catalysis and substrate binding trans-cyclopropane synthetase which contain a group of eight amino acid segment coded by gene CmaA2. [13]

\subsection{Drugs used as targets.}

Drugs are used against the target MMA4 and cmaA2, which involves the synthesis of mycolic acid, which is highly seen in the cell wall of the Mycobacterium tuberculosis. These chosen drug name and primary use are listed in (Table 1) shows effective antibacterial, cell wall synthesis inhibitor, and Beta-lactamase inhibitor. Beta-lactamase is the enzyme that develops resistance against antibiotics and which turns into multidrug resistance. Here, few drugs are stable in the presence of Beta-lactamase, and others are used to treat both grams positive and negative bacterial infection like acne, urinary tract infection, etc. [14-17]. 


\section{Materials and Methods}

2.1. Software application.

\subsubsection{Cygwin.}

It is essentially an open software consisting of a collection of tools that allows applications of UNIX or Linux to be compiled and run on a Windows operating system from an interface like Linux. This capability can help developers move applications from UNIX or Linux to Windows-based systems, and thus makes it easier to support their applications running on the Windows platform [18] (http://www.cygwin.com)

\subsubsection{MGL tools.}

The Molecular Graphics Laboratory supports the Auto dock 4.2.6 software for the successful completion of the docking procedure. (http://www.mgltools.scripps.edu/downloads).

\subsubsection{Auto dock 4.2.6.}

Predominantly used free software tool designed for molecular docking used to predict protein-ligand binding interaction in 3D structure $\left[\begin{array}{ll}19, & 20] \text {. }\end{array}\right.$ (http://autodock.scripps.edu/downloads/autodock-4-2-x-installation-on-windows)

\subsubsection{Open babel.}

Software used to convert the chemical file format. Where we can convert ligand 2D SDF format into 3D PDB format. (http://openbabel.org/wiki/Get_Open_Babel)

\subsubsection{Discovery studio visualizer.}

Software tool helps to visualize molecular interaction between protein-ligand. It supports to visualization of small molecules to large molecules. (https://www.3dsbiovia.com/products/collaborative-science/biovia-discoverystudio/visualization-download.php).

\subsection{Ligand preparation.}

FDA approved ligands, namely Cefpodoxime, Avibactam, Lymecycline, Clofazimine, Meropenem, Clavulanate, 6-Fluoroquinolone, Sulbactam, Cephalosporin and Tazobactam are retrieved from PubChem (https://pubchem.ncbi.nlm.nih.gov/) in 2D SDF format. The ligand converted into 3D PDB format using computer software open babel.

\subsection{Protein preparation.}

The target protein involves in the synthesis of mycolic acid, which is present in the cell wall of the bacteria encoded by gene Methoxy mycolic acid synthase 4 (MMA4) and cyclopropane mycolic acid synthase (cmaA2) synthesis by mycobacterium tuberculosis. The structures are computing from protein data bank (PDB) (https://www.rcsb.org/) in 3D PDB format. 


\subsection{Molecular docking analysis.}

In silico analysis, AUTODOCK 4 is used to determine the binding possibility of the selected ligand with that of the active site of the target molecule [21, 22]. Methoxy mycolic acid synthase 4 (MMA4) and cyclopropane mycolic acid synthase (cmaA2). The latest version of autodock, i.e., autodock4 steps, involves the addition of polar /non-polar hydrogen bonds. Initially, Gasteiger/Kollman charges are added to the target molecule [23]. This is followed by saving ligand and target protein in pdbqt format with updated features flexibility of side chains in the target during the process of ligand docking based on Lamarckian Genetic Algorithm. For MMA4 and cmaA2 targets, the grid $\mathrm{x}$, $\mathrm{y}$ and $\mathrm{z}$ were designed as $60 \times 60 \times 60$; other remaining parameters were set as default. The docked protein-ligand complex with lower binding energy based on linear regression analysis is considered a good inhibitor for the chosen target, and further studies are carried out [24, 25].

\section{Results and Discussion}

Primarily rifampicin, pyrazinamide, Isoniazid, and ethambutol are considered the most effective First-line and second-line anti-tuberculosis therapeutic drugs used to bacterial infection Mycobacterium tuberculosis [26- 28]. Though this drug inhibits bacterial growth and performs as a good therapeutic drug on another side, it causes several side effects because of its toxicity and rapid development of drug resistance [29], computational virtual screening of FDA approval may help to identify the best existing drug for tuberculosis to overcome drug resistance and reduce the toxic effect and also in cost and time effective [30, 31].

a. Cefpodoxime

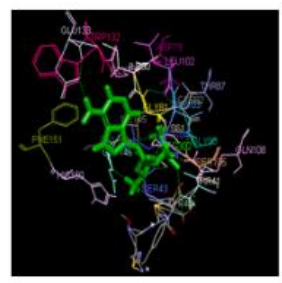

f. Clavulaanate

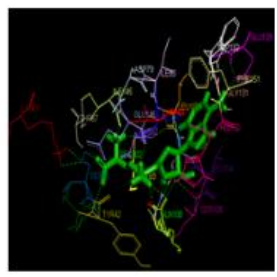

b. Avibactam

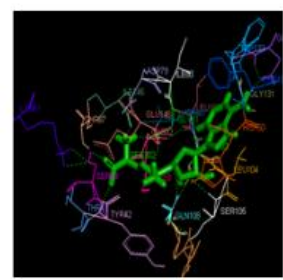

g. 6-Fluoroquinolone

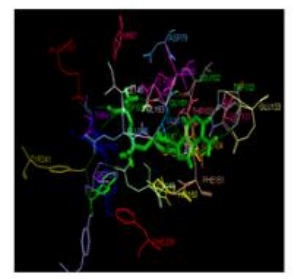

c. Lymecycline

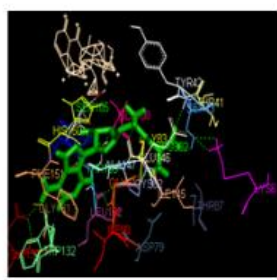

h. Sulbactam

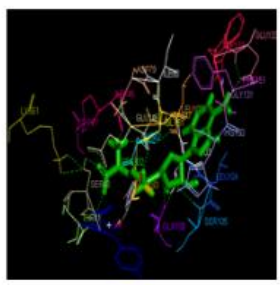

d. Clofazimine

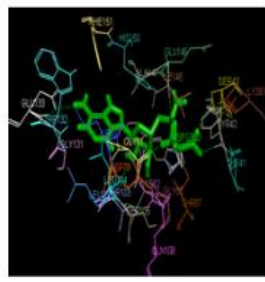

i. Cephalosporin

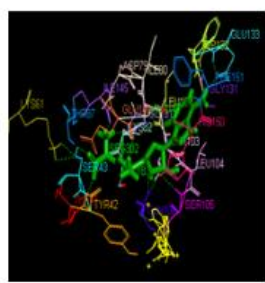

e. Meropenem

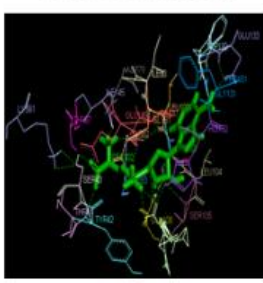

j. Tazobactam

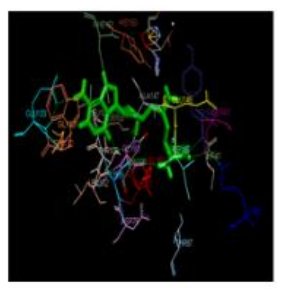

Figure 1. Visualization of target protein MMA4 interaction with FDA-approved drugs.

Mycolic acid present in the cell wall Mycobacterium tuberculosis remains an important target in developing anti-tuberculosis therapeutic treatment. Mycolic acid synthase contributes virulence factor in the infectious disease caused by the bacterial microorganism Mycobacterium tuberculosis. The biosynthesis of oxygenated mycolic acid synthase required functional protein Hydroxymycolate synthase and Cyclopropane mycolic acid synthase 2. MMA4 gene-coded protein Hydroxymycolate synthase act as a precursor in the synthesis hydroxymycolate. CmaA2 gene acts as catalyzing in the formation of cyclopropanated keto or methoxymycolate coded protein Cyclopropane mycolic acid synthase 2. A based study 
conducted on mice, by rendering the hma genes (MMA4 and cmaA) inactive, no synthesis of mycolic acid is observed.

a. Cefpodoxime

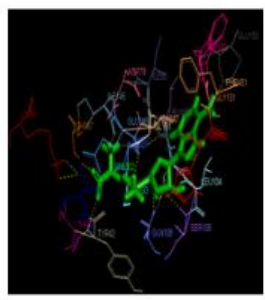

f. Clavulaanate

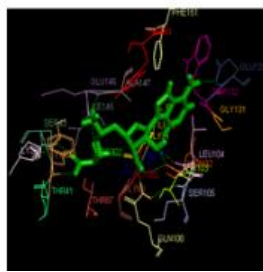

b. Avibactam

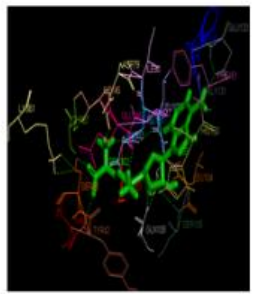

g. 6-Fluoroquinolone

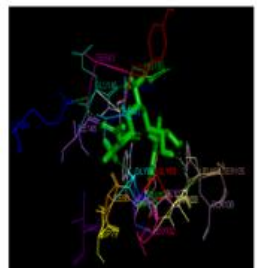

c. Lymecycline

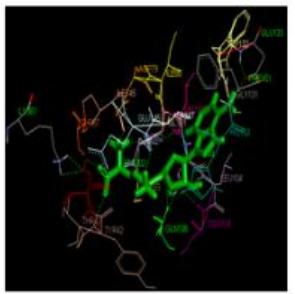

h. Sulbactam

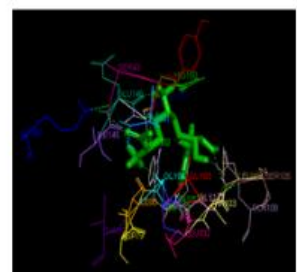

d. Clofazimine

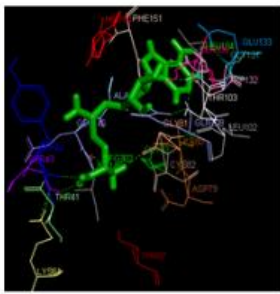

i. Cephalosporin

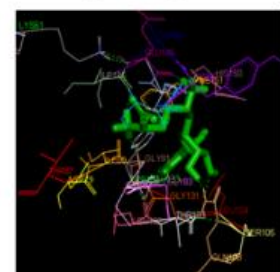

e. Meropenem

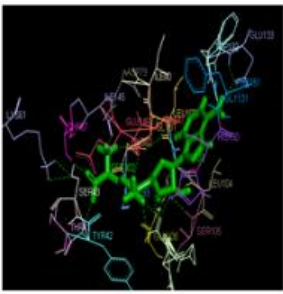

j. Tazobactam

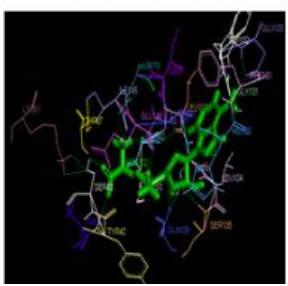

Figure 2. Visualization of target protein cmaA2 interaction with FDA-approved drugs.

Table 1. Drugs are used as Targets and their primary use (https://pubchem.ncbi.nlm.nih.gov/).

\begin{tabular}{l|l|l|l|l} 
S.no & Drug & Molecular formula & Property & Action/medical application \\
\hline 01. & Cefpodoxime & $\mathrm{C}_{15} \mathrm{H}_{17} \mathrm{~N}_{5} \mathrm{O}_{6} \mathrm{~S}_{2}$ & Antibacterial \\
Beta-lactamase inhibitor & $\begin{array}{l}\text { Inhibits cell wall synthesis. } \\
\text { Treatment of Sinus infection, acute } \\
\text { otitis media, pharyngitis. }\end{array}$ \\
\hline 02. & Avibactam & $\mathrm{C}_{7} \mathrm{H}_{11} \mathrm{~N}_{3} \mathrm{O}_{6} \mathrm{~S}$ & Antimicrobial agent & $\begin{array}{l}\text { Treatment of urinary tract infection } \\
\text { and intra-abdominal infections. }\end{array}$ \\
\hline 03. & Lymecycline & $\mathrm{C}_{29} \mathrm{H}_{38} \mathrm{~N}_{4} \mathrm{O}_{10}$ & Antibiotic & $\begin{array}{l}\text { Treatment of acne and bacterial } \\
\text { infection. }\end{array}$ \\
\hline 04. & Clofazimine & $\mathrm{C}_{27} \mathrm{H}_{22} \mathrm{Cl}_{2} \mathrm{~N}_{4}$ & $\begin{array}{l}\text { Anti-mycobacterial and } \\
\text { Anti-inflammatory }\end{array}$ & Treatment of multibacillary leprosy \\
\hline 05. & Meropenem & $\mathrm{C}_{17} \mathrm{H}_{25} \mathrm{~N}_{3} \mathrm{O}_{5} \mathrm{~S}$ & Antibacterial & $\begin{array}{l}\text { Treatment of skin infection caused by } \\
\text { meningitis and bacteria. }\end{array}$ \\
\hline 06. & Clavulanate & $\mathrm{C}_{8} \mathrm{H}_{9} \mathrm{NO}_{5}$ & Beta-lactamase inhibitor & $\begin{array}{l}\text { Treatment of pneumonia, ear } \\
\text { infections, bronchitis. }\end{array}$ \\
\hline 07. & $\begin{array}{l}6- \\
\text { fluoroquinolone }\end{array}$ & $\mathrm{C}_{9} \mathrm{H}_{6 \mathrm{FN}}$ & Antibiotic & $\begin{array}{l}\text { Treatment of respiratory tract, } \\
\text { kidney, skin infection. }\end{array}$ \\
\hline 08. & Sulbactam & $\mathrm{C}_{8} \mathrm{H}_{11} \mathrm{NO}_{5} \mathrm{~S}$ & $\begin{array}{l}\text { semisynthetic Beta- } \\
\text { lactamase inhibitor }\end{array}$ & $\begin{array}{l}\text { Prevent antibiotic resistance caused } \\
\text { by Beta-lactamase. Treatment of skin } \\
\text { and abdomen bacterial infection. }\end{array}$ \\
\hline 09. & Tazobactam & $\mathrm{C}_{10} \mathrm{H}_{12} \mathrm{~N}_{4} \mathrm{O}_{5} \mathrm{~S}$ & Beta-lactamase inhibitor & $\begin{array}{l}\text { Treatment of Pneumonia, stomach } \\
\text { and skin infection. }\end{array}$ \\
\hline 10. & Cephalosporin & $\mathrm{C}_{15} \mathrm{H}_{21} \mathrm{~N}_{3} \mathrm{O}_{7} \mathrm{~S}$ & Beta-lactam antibiotic & $\begin{array}{l}\text { Treatment for strep throat and urinary } \\
\text { tract infections }\end{array}$
\end{tabular}

Table 2. Binding Energies of the Drug with Target MMA4 and CMAA2.

\begin{tabular}{l|l|l|l|l|l|l|l}
$\begin{array}{l}\text { Sl. } \\
\text { No. }\end{array}$ & Drug name & $\begin{array}{l}\text { Pub } \\
\text { chem id }\end{array}$ & $\begin{array}{l}\text { 3d structure of the } \\
\text { drugs }\end{array}$ & $\begin{array}{l}\text { Binding } \\
\text { energy with } \\
\text { target } \\
\text { MMA4 }\end{array}$ & Rank & $\begin{array}{l}\text { Binding } \\
\text { energy with } \\
\text { target cmaa2 }\end{array}$ & Rank \\
\hline & & & & & & & \\
A & Cefpodoxime & 6335986 & & & -5.65 & & 7
\end{tabular}




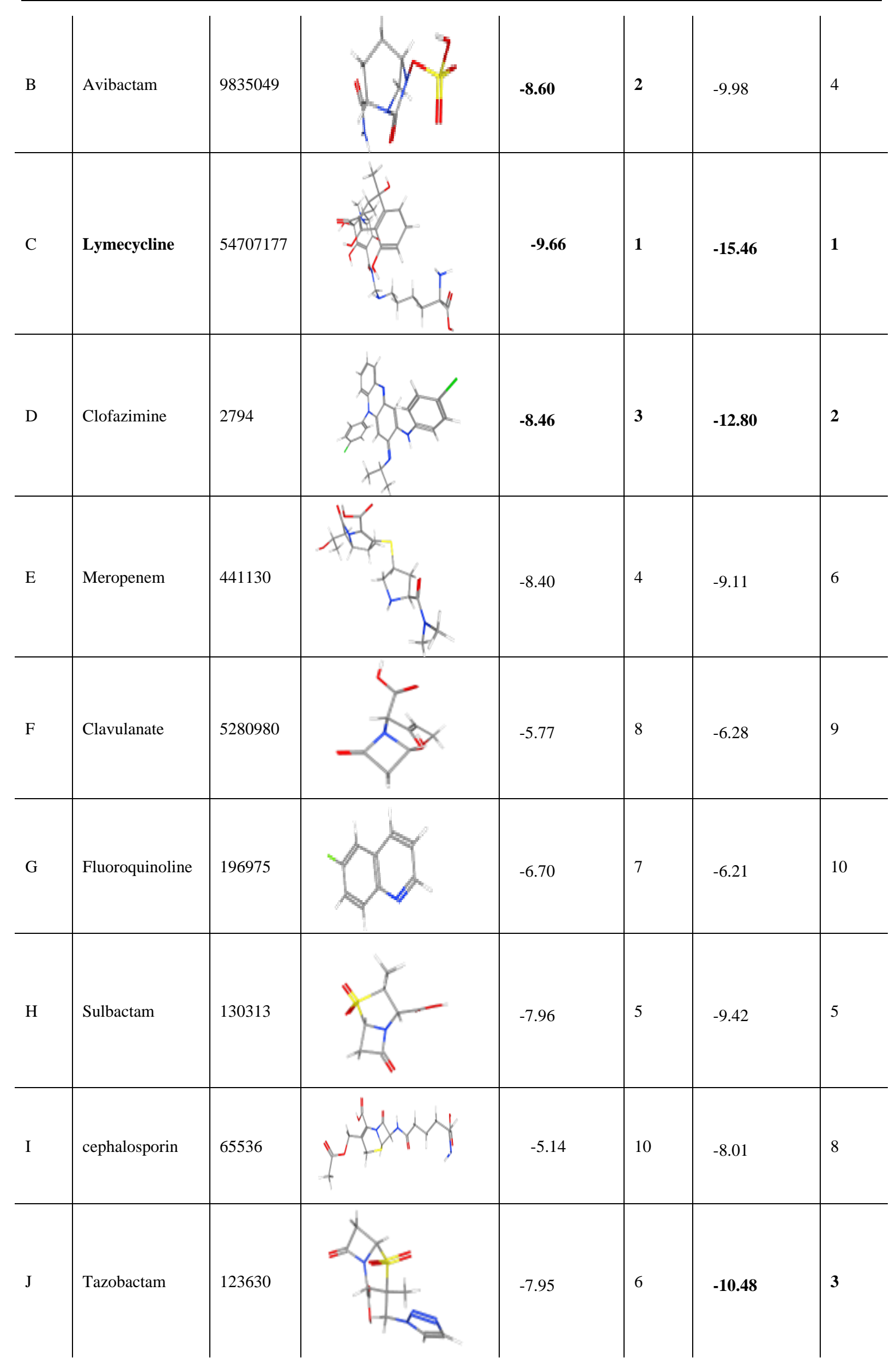


In this study, we performed In silico analysis using AutoDock4.2.6 software to explore and identify potential drug, which Strongly acts as an inhibitor against target [32,33] MMA4 CmaA2 to interrupt the synthesis of oxygenated mycolic acid. Molecular docking is attained to determine the best potential drug against target MMA4 and CmaA2 through binding efficiency and interaction of the ligand with the target [34, 35] (Figure 1 and Figure 2).

\section{Conclusion}

Among selected 10 FDA approved drugs, namely cefpodoxime, avibactam, lymecycline, clofazimine, meropenem, clavulanate, 6-fluoroquinolone, sulbactam, cephalosporin, and tazobactam for target MMA4 drugs lymecycline, avibactam, and clofazimine with binding energy $-9.66,-8.60$, and -8.46 against target identified as a top potential drug. For target $\mathrm{CmaA} 2$ drugs, lymecycline, clofazimine, and tazobactam with binding energy $-15.46,-12.80$, and -10.48 identified as a top potential drug with well binding interaction (Table 2). Molecular docking analysis revealed lymecycline interacts well with the target MMA4 and CmaA2 with a low binding energy of -9.66 and -15.46 , respectively, indicating active site strength binds with a ligand. Virtual screening significant that lymecycline acts as a strong inhibitor and interrupt the function of target gene MMA4 and CmaA2. Among 10 FDA-approved drugs to identify the best inhibitor against two target MMA4 and CmaA2, which involves in oxygenated mycolic acid synthesis of Mycobacterium tuberculosis by performing virtual ligand-based screening results that lymecycline will be promising and potential drug with lower binding energy value -9.66 and -15.46 against target MMA4 and CmaA2 respectively.

\section{Funding}

Ministry of Science and Technology, Department of Science and Technology (KIRAN Division) (GoI), New Delhi. (Ref No. DST/WOSB/ 2018/1583-HFN (G)).

\section{Acknowledgments}

The authors gratefully acknowledge the Ministry of Science and Technology, Department of Science and Technology (KIRAN Division) (GoI), New Delhi. (Ref No. DST/WOSB/ 2018/1583-HFN (G)). The authors are also thankful to B.S. Abdur Rahman Institute of Science $\&$ Technology, Chennai, provides research facilities in the School of Life Sciences.

\section{Conflicts of Interest}

The authors declare no conflict of interest.

\section{References}

1. Global Tuberculosis Report 2019 - World Health Organization https://www.who.int/tb/global-report-2019.

2. Centre for disease control and prevention. https://www.cdc.gov/tb/default.htm.

3. Mhango, D.V.; Mzinza, D.T.; Jambo, K.C.; Mwandumba, H.C. New management approaches to tuberculosis in people living with HIV. Curr Opin Infect Dis 2020, 10, https://doi.org/10.1097/QCO.0000000000000704.

4. Rodrigues, L.; Cravo, P.; Viveiros, M. Efflux pump inhibitors as a promising adjunct therapy against drug resistant tuberculosis: a new strategy to revisit mycobacterial targets and repurpose old drugs. Expert review of anti-infective therapy 2020, 18, 741-757, https://doi.org/10.1080/14787210.2020.1760845.

5. Battah, B.; Chemi, G.; Butini, S.; Campiani, G.; Brogi, S.; Delogu, G.; Gemma, S. A Repurposing Approach for Uncovering the Anti-Tubercular Activity of FDA-Approved Drugs with Potential Multi-Targeting Profiles. Molecules 2019, 24, https://doi.org/10.3390/molecules24234373. 
6. Rani, J.; Silla, Y.; Borah, K.; Ramachandran, S.; Bajpai, U. Repurposing of FDA-approved drugs to target MurB and MurE enzymes in Mycobacterium tuberculosis. Journal of Biomolecular Structure and Dynamics 2020, 38, 2521-2532, https://doi.org/10.1080/07391102.2019.1637280.

7. Schroeder, E.K.; Souza, O.N.d.; Santos, D.S.; Blanchard, J.S.; Basso, L.A. Drugs that Inhibit Mycolic Acid Biosynthesis in Mycobacterium tuberculosis. Current Pharmaceutical Biotechnology 2002, 3, 197-225, https://doi.org/org/10.2174/1389201023378328.

8. Boissier, F.; Bardou, F.; Guillet, V.; Uttenweiler-Joseph, S.; Daffé, M.; Quémard, A.; Mourey, L. Further Insight into S-Adenosylmethionine-dependent Methyltransferases Structural characterization of hma, an enzyme essential for the biosynthesis of oxygenated mycolic acids in mycobacterium tuberculosis. $J$ Biol Chem 2006, 281, 4434-45, https://doi.org/10.1074/jbc.M510250200.

9. Dubnau, E.; Chan, J.; Raynaud, C.; Mohan, V.P.; Lanéelle, M.-A.; Yu, K.; Quémard, A.; Smith, I.; Daffé, M. Oxygenated mycolic acids are necessary for virulence of Mycobacterium tuberculosis in mice. Molecular Microbiology 2000, 36, 630-637, https://doi.org/10.1046/j.1365-2958.2000.01882.x.

10. Sai Nivetha, S.; Ranjani, S.; Hemalatha, S. Synthesis and application of silver nanoparticles using Cissus quadrangularis. Inorg. Nano-Met. Chem 2020, 1-8, https://doi.org/10.1080/24701556.2020.1862219.

11. Borah, P.; Deb, P.K.; Venugopala, K.N.; Al-Shar'i, N.A.; Singh, V.; Deka, S.; Srivastava, A.; Tiwari, V.; Mailavaram, R.P. Tuberculosis: An Update on Pathophysiology, Molecular Mechanisms of Drug Resistance, Newer Anti-TB Drugs, Treatment Regimens and Host-Di-rected Therapies. Curr Top Med Chem 2020, 11, https://doi.org/10.2174/1568026621999201211200447.

12. Grover, S.; Gangwar, R.; Jamal, S.; Ali, S.; Nisaa, K.; Ehtesham, N.Z.; Hasnain, S.E. Mycobacterial Methyltransferases: Significance in Pathogenesis and Virulence. In: Mycobacterium Tuberculosis: Molecular Infection Biology, Pathogenesis, Diagnostics and New Interventions. Hasnain, S.E.; Ehtesham, N.Z.; Grover, S. Eds. Springer Singapore: Singapore, 2019; https://doi.org/10.1007/978-981-32-9413-4_7.

13. Annaraj P, D.; Kadirvel, P.; Subramanian, A.; Anishetty, S. Free enzyme dynamics of CmaA3 and CmaA2 cyclopropane mycolic acid synthases from Mycobacterium tuberculosis: Insights into residues with potential significance in cyclopropanation. Journal of Molecular Graphics and Modelling 2019, 91, 61-71, https://doi.org/10.1016/j.jmgm.2019.05.016.11.

14. Singh, A.; Somvanshi, P.; Grover, A. Drug repurposing against arabinosyl transferase (EmbC) of Mycobacterium tuberculosis: Essential dynamics and free energy minima based binding mechanics analysis. Gene 2019, 693, 114-126, https://doi.org/10.1016/j.gene.2019.01.029.

15. Kumar, A.; Boradia, V.M.; Thakare, R.; Singh, A.K.; Gani, Z.; Das, S.; Patidar, A.; Dasgupta, A.; Chopra, S.; Raje, M.; Raje, C.I. Repurposing ethyl bromopyruvate as a broad-spectrum antibacterial. Journal of Antimicrobial Chemotherapy 2019, 74, 912-920, https://doi.org/10.1093/jac/dky555.

16. Kumar, A.; Alam, A.; Grover, S.; Pandey, S.; Tripathi, D.; Kumari, M.; Rani, M.; Singh, A.; Akhter, Y.; Ehtesham, N.Z.; Hasnain, S.E. Peptidyl-prolyl isomerase-B is involved in Mycobacterium tuberculosis biofilm formation and a generic target for drug repurposing-based intervention. npj Biofilms and Microbiomes 2019, 5, https://doi.org/10.1038/s41522-018-0075-0.

17. Gl, B.; Rajput, R.; Gupta, M.; Dahiya, P.; Thakur, J.K.; Bhatnagar, R.; Grover, A. Structure-based drug repurposing to inhibit the DNA gyrase of Mycobacterium tuberculosis. Biochemical Journal 2020, 477, 4167-4190, https://doi.org/10.1042/BCJ20200462.

18. Begum, S.M.F.M.; Priya, S.; Sundararajan, R.; Hemalatha, S. Novel anticancerous compounds from Sargassum wightii: In silico and in vitro approaches to test the antiproliferative efficacy. Journal of Advanced Pharmacy Education \& Research 2017, 7, 272-7.

19. Lutfiya, A.S.; Priya, S.; Manzoor, M.A.P.; Hemalatha, S. Molecular docking and interactions between vascular endothelial growth factor (VEGF) receptors and phytochemicals: An in-silico study. Biocatalysis and Agricultural Biotechnology 2019, 22, https://doi.org/10.1016/j.bcab.2019.101424.

20. Sharma, A.; Islam, M.H.; Fatima, N.; Upadhyay, T.K.; Khan, M.K.A.; Dwivedi, U.N.; Sharma, R. Elucidation of marine fungi derived anthraquinones as mycobacterial mycolic acid synthesis inhibitors: an in silico approach. Molecular Biology Reports 2019, 46, 1715-1725, https://doi.org/10.1007/s11033-01904621-0.

21. Begum, S.M.F.; Priya, S.; Hemalatha, S. In vitro and In silico analysis of the Anti oxidant and Angiogenic potential of Padina tetrastomatica. Int. J. Pharmtech Res 2017, 10, 223-30.

22. Burley, K.H.; Cuthbert, B.J.; Basu, P.; Newcombe, J.; Irimpan, E.M.; Quechol, R.; Foik, I.P.; Mobley, D.L.; Beste, D.J.V.; Goulding, C.W. Structural and Molecular Dynamics of Mycobacterium tuberculosis Malic Enzyme, a Potential Anti-TB Drug Target. ACS Infectious Diseases 2021, 7, 174-188, https://doi.org/10.1021/acsinfecdis.0c00735.

23. Priya, S.; Kumar, N.S.; Hemalatha, S. Antiviral phytocompounds target envelop protein to control Zika virus. Computational Biology and Chemistry 2018, 77, 402-412, https://doi.org/10.1016/j.compbiolchem.2018.08.008.

24. Umumararungu, T.; Mukazayire, M.J.; Mpenda, M.; Mukanyangezi, M.F.; Nkuranga, J.B.; Mukiza, J.; Olawode, E.O. A review of recent advances in anti-tubercular drug development. Indian Journal of Tuberculosis 2020, 67, 539-559, https://doi.org/10.1016/j.ijtb.2020.07.017. 
25. Bvumbi, M.V. Activity of Riminophenazines against Mycobacterium tuberculosis: A Review of Studies that Might be Contenders for Use as Antituberculosis Agents. ChemMedChem 2020, 15, 2207-2219, https://doi.org/10.1002/cmdc.202000580.

26. Patel, Y.S.; Mistry, N.; Mehra, S. Repurposing artemisinin as an anti-mycobacterial agent in synergy with rifampicin. Tuberculosis 2019, 115, 146-153, https://doi.org/10.1016/j.tube.2019.03.004.

27. Yew, W.W.; Chang, K.C.; Chan, D.P.; Zhang, Y. Metformin as a host-directed therapeutic in tuberculosis: Is there a promise? Tuberculosis 2019, 115, 76-80, https://doi.org/10.1016/j.tube.2019.02.004.

28. Pushkaran, A.C.; Vinod, V.; Vanuopadath, M.; Nair, S.S.; Nair, S.V.; Vasudevan, A.K.; Biswas, R.; Mohan, C.G. Combination of Repurposed Drug Diosmin with Amoxicillin-Clavulanic acid Causes Synergistic Inhibition of Mycobacterial Growth. Scientific Reports 2019, 9, https://doi.org/10.1038/s41598-019-43201$\mathrm{x}$.

29. Mourenza, Á.; Gil, J.A.; Mateos, L.M.; Letek, M. Novel Treatments against Mycobacterium tuberculosis Based on Drug Repurposing. Antibiotics 2020, 9, https://doi.org/10.3390/antibiotics9090550.

30. Arpudhamary, V.; Priya, S.; Manzoor, M.A.P.; Mubarakali, D.; Hemalatha, S. Apoptotic-inducing factor 1 (AIF1) plays a critical role in cembranoid mediated apoptosis to control cancer: Molecular docking and dynamics study. Biocatalysis and Agricultural Biotechnology 2019, 22, https://doi.org/10.1016/j.bcab.2019.101343.

31. Kanvatirth, P.; Jeeves, R.E.; Bacon, J.; Besra, G.S.; Alderwick, L.J. Utilisation of the Prestwick Chemical Library to identify drugs that inhibit the growth of mycobacteria. PLOS ONE 2019, 14, https://doi.org/10.1371/journal.pone.0213713.

32. Sabiha Sulthana, H.B.; Ranjani, S.; Hemalatha, S. Comparison of efficacy of nanoparticles synthesized from leaves and flowers of Russelia equisitiformis. Inorganic and Nano-Metal Chemistry 2020, https://doi.org/10.1080/24701556.2020.1862218.

33. Naicker, N.; Sigal, A.; Naidoo, K. Metformin as Host-Directed Therapy for TB Treatment: Scoping Review. Frontiers in Microbiology 2020, 11, https://doi.org/10.3389/fmicb.2020.00435.

34. Maitra, A.; Evangelopoulos, D.; Chrzastek, A.; Martin, L.T.; Hanrath, A.; Chapman, E.; Hailes, H.C.; Lipman, M.; McHugh, T.D.; Waddell, S.J.; Bhakta, S. Carprofen elicits pleiotropic mechanisms of bactericidal action with the potential to reverse antimicrobial drug resistance in tuberculosis. Journal of Antimicrobial Chemotherapy 2020, 75, 3194-3201, https://doi.org/10.1093/jac/dkaa307.

35. Khan, A.; Singh, V.K.; Mishra, A.; Soudani, E.; Bakhru, P.; Singh, C.R.; Zhang, D.; Canaday, D.H.; Sheri, A.; Padmanabhan, S.; Challa, S.; Iyer, R.P.; Jagannath, C. NOD2/RIG-I Activating Inarigivir Adjuvant Enhances the Efficacy of BCG Vaccine Against Tuberculosis in Mice. Frontiers in Immunology 2020, 11, https://doi.org/10.3389/fimmu.2020.592333. 